\title{
Nitrate Concentration in the Guliya Ice Core and Solar Activity
}

The sun is a major forcing factor of climatic and environmental changes on the Earth. Its activity can be reflected in the concentrations of ${ }^{10} \mathrm{Be}$ and $\mathrm{NO}_{3}^{-}$in ice cores. To date, such work has been done only in polar regions. In addition, there is still some question as to whether variations of $\mathrm{NO}_{3}^{-}$concentration or flux correlate with solar activity. Here, this question is discussed, based on $\mathrm{NO}_{3}{ }^{-}$ concentration recorded in an ice core from the Guliya Ice Cap in the middle latitudes of the Northern Hemisphere.

The Guliya Ice Cap, on the Tibetan Plateau, is a favorable sites for ice core studies. In 1992, a deep ice core, about $309 \mathrm{~m}$ long, was recovered successfully by scientists from the Lanzhou Institute of Glaciology and Geocryology, China, and Byrd Polar Research Center, USA. For chemical analyses, the sampling interval was $3 \mathrm{~cm}$. $\mathrm{NO}_{3}{ }^{-}$concentration was measured through ion chromatography after melting the snow / ice samples in plastic bottles, treated with distilled water, at room temperature. The dating of the core has been reported in previous publications. Here, we discuss the records of $\mathrm{NO}_{3}^{-}$concentration in the upper $107.6 \mathrm{~m}$ of the Guliya ice core, containing 1032 annual layers.

Spectral analysis of the variations of $\mathrm{NO}_{3}{ }^{-}$concentration shows that there are some significant periodicities which coincide with periodicities of the solar activity. The most significant periodicity in the variations of $\mathrm{NO}_{3}{ }^{-}$concentration is 22.9 years, which is close to the solar magnetic cycle. The other periodicities are 88.1, 31.3, 5.5 and 10.3 years, among which 88.1 and 10.3 correspond to the solar Gleissberg (or Century) and sunspot cycles respectively. Recently we analyzed variations in length of the sunspot cycle for the last 2000 years. A cycle of about 36 years was found. The length of this cycle changed from 28 to 42 years during different periods, probably indicating that solar activity has this cycle as recorded in variations of $\mathrm{NO}_{3}^{-}$concentration.

Comparison between the variations of $\mathrm{NO}_{3}^{-}$concentration and sunspot number during the period from 1749 to 1991, indicates that the trends of variation are similar. The length of the sunspot cycle is an indicator of the solar activity. High solar activity implies short

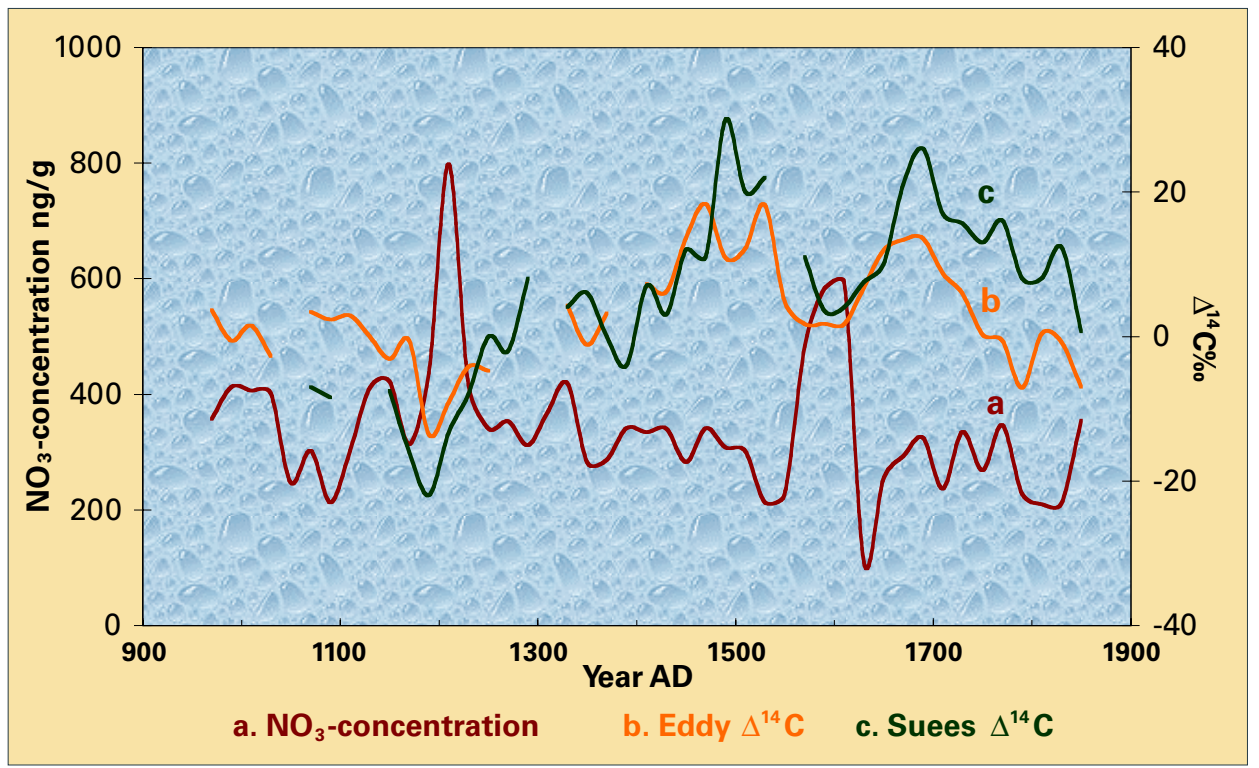

Figure 1: The variations of 20 year mean $\mathrm{NO}_{3}^{-}$concentration in the Guliya ice core and $\Delta^{14} \mathrm{C}$ in tree rings during the period from $A D 960$ to 1860.

sunspot cycles whereas long sunspot cycles are characteristic of low solar activity levels. We investigate variations in $\mathrm{NO}_{3}{ }^{-}$concentration and sunspot cycle length. A negative correlation between their secular trends is found. Another indicator of the solar activity is $\Delta^{14} \mathrm{C}$ in tree rings. The higher the solar activity, the smaller the value of $\Delta^{14} \mathrm{C}$; and vice versa. Fig. 1 shows variations of 20 year mean $\mathrm{NO}_{3}{ }^{-}$concentration and $\Delta^{14} \mathrm{C}$ for the past 1000 years. Because human consumption of fossil fuel has made $\Delta^{14} \mathrm{C}$ in tree rings unable to indicate the intensity of the solar activity since industrialization, only the data of $\Delta^{14} \mathrm{C}$ before industrialization are shown here. In Fig. 1, the negative correlation between $\Delta^{14} \mathrm{C}$ and $\mathrm{NO}_{3}{ }^{-}$concentration can be seen clearly. Together, they indicate a significant positive correlation between $\mathrm{NO}_{3}{ }^{-}$concentration in the Guliya ice core and solar activity. Moreover, the Maunder Minimum (1640 1710 AD) and the maximum of the Middle Ages (1120 1280 AD) are also seen in Fig. 1. The high $\mathrm{NO}_{3}{ }^{-}$concentrations around $1600 \mathrm{AD}$ are related to solar activity. In documentary archives from China, there are only 33 records of sunspots in the 17th century, but 17 records emerged in the first 30 years of that century (accounting for $51.5 \%$ of the total records). In the documents of central Europe, there were 292 records of aurora from 1580 1700
$\mathrm{AD}$, of which 168 records were during 1580 1630 AD (accounting for 57.5\%).

In conclusion, the positive correlation between $\mathrm{NO}_{3}{ }^{-}$concentration in the Guliya ice core and the solar activity suggests an important influence of solar activity on $\mathrm{NO}_{3}^{-}$concentration in this core.

\section{Wang Ninglan, Yao Tandong}

Laboratory of lce Core and Cold Regions Environment, Lanzhou Institute of Glaciology and Geocryology, Chinese Academy of Sciences, Lanzhou, China

\section{LONNIE G. THOMPSON}

Byrd Polar Research Center, Ohio State University, USA

thompson.3@osu.edu

PAES Newsletter 2000-2
ISSN 1563-0803
Editors: Keith Alverson and Frank Oldfield
Guest Editor: Vera Markgraf
Layout: Niklaus Schranz
The PAGES International Project Office and its
publications are supported by the Swiss and
US National Science Foundations
Printed on recycled paper

